\title{
Combination therapy with DPP-4 inhibitors and pioglitazone in type 2 diabetes: theoretical consideration and therapeutic potential
}

\author{
Nasser Mikhail \\ Endocrinology Division, \\ Olive View-UCLA Medical Center, \\ David-Geffen School of Medicine, \\ CA, USA
}

Correspondence: Nasser Mikhail, MD, MSc David-Geffen School of Medicine, 14445

Olive View Drive, Sylmar, CA, USA 91342

$\mathrm{Tel}+\mathrm{I} 8183643205$

$\mathrm{Fax}+\mathrm{I} 8183644573$

Email nmikhail@ladhs.org

\begin{abstract}
Sitagliptin and vildagliptin represent a new class of anti-diabetic agents that enhance the action of incretin hormones through inhibition of dipeptidyl peptidase-4 (DPP-4), the enzyme that normally inactivates incretin hormones. Because of their distinct mechanism of action, DPP-4 inhibitors can be used as add-on therapy to other classes of drugs for treatment of type 2 diabetes. The objective of this review is to critically evaluate clinical trials of sitagliptin and vildagliptin in combination with pioglitazone. The addition of either sitagliptin or vildagliptin to ongoing pioglitazone therapy is associated with reduction in average hemoglobin A1c (HbA1c) levels of approximately $0.7 \%$ compared with placebo and $1 \%$ compared with baseline after 24 weeks. When started concomitantly in drug-naïve patients, the combination of pioglitazone $30 \mathrm{mg}$ and vildagliptin $100 \mathrm{mg}$ qd reduces $\mathrm{HbA} 1 \mathrm{c}$ by $1.9 \%$ after 24 weeks, compared with $1.1 \%$ with pioglitazone monotherapy. In general, the addition of DPP-4 inhibitors to pioglitazone was well tolerated, did not increase the incidence of hypoglycemia, and did not substantially worsen the weight-gain induced by pioglitazone. The combination of sitagliptpin or vildagliptin with pioglitazone can be a useful therapeutic approach in patients with type 2 diabetes who cannot tolerate metformin or a sulfonylurea.
\end{abstract}

Keywords: incretins, sitagliptin, vildagliptin, dipeptidyl peptidase inhibitors, pioglitazone, type 2 diabetes

\section{Introduction}

The anti-diabetic actions of the DPP-4 inhibitors are based on the two incretin hormones glucagon-like peptide 1 (GLP-1) and gastric inhibitory polypeptide (GIP). Both GLP-1 and GIP stimulate insulin secretion after meals. Moreover, GLP-1 exerts additional actions that target postprandial hyperglycemia: inhibition of postprandial glucagon secretion, delay of gastric emptying, and possible induction of early satiety (Drucker and Nauck 2006; Mikhail 2006). However, it was not practical to directly use GLP-1 and GIP as pharmacological agents for treatment of diabetes because of their very short half-lives as result of their rapid breakdown by the enzyme DPP-4. For example, the half-life of GLP-1 is approximately 2 minutes after intravenous administration (Visboll et al 2003). To overcome this problem, inhibitors of the enzyme DPP-4 were used as alternatives to GLP-1 and GIP. Thus, DPP-4 inhibitors, also called incretin enhancers, prolong the effects of native GLP-1 and GIP and increase their serum levels by approximately 2-fold (Drucker and Nauck 2006). The best-studied DPP-4 inhibitors are sitagliptin and vildagliptin. The two drugs stimulate insulin secretion and inhibit glucagon release after meals (Drucker and Nauck 2006; Mikhail 2006). They do not delay gastric emptying or induce early satiety presumably because the rise in GLP-1 circulating levels is not sufficiently high to exert such effects (Drucker and Nauck 2006; Vella et al 2007). Available evidence does not support consistent effects 
of DPP-4 inhibitors on insulin sensitivity (Pratley et al 2006; Raz et al 2006; Rosenstock et al 2006; Garber et al 2007, 2008; Hanefeld et al 2007; Azuma et al 2008; Utzschneider et al 2008). On the other hand, improving insulin sensitivity is the main mechanism whereby thiazolidinediones (TZDs) lower plasma glucose (Yki-Jarvinen 2004). Therefore, due to the marked differences in mechanisms of actions between DPP-4 inhibitors and TZDs, it was plausible to evaluate the therapeutic potential of the combination between the 2 drug classes. This article will focus on the two DPP-4 inhibitors sitagliptin (Januvia ${ }^{\circledR}$, Merck and Co., Inc.) and vildagliptin (Galvus $^{\circledR}$, Novartis) as part of combination therapy with the TZD pioglitazone for treatment of type 2 diabetes. Sitagliptin received Federal Drug Administration (FDA) approval in October 2006. Vildagliptin has not yet been approved in the USA, but the drug is used in Mexico and Brazil. Combination therapy formed of DPP-4 inhibitors and metformin has been reviewed in a recent issue of this journal (Ahren 2008).

\section{Clinical trials of DPP-4 inhibitors plus pioglitazone}

The combination of pioglitazone and DPP-4 inhibitors in type 2 diabetes was evaluated in 3 trials of 24-week duration each. Two of the three trials evaluated the addition of sitagliptin or vildagliptin to ongoing pioglitazone therapy (Rosenstock et al 2006; Garber et al 2007), whereas the third trial evaluated the concomitant initiation of both vildagliptin and pioglitazone in drug-naïve patients (Rosenstock et al 2007). An overview and the main results of those studies are summarized in Table 1. No trials have been published on the combination between DPP-4 inhibitors and the second TZD rosiglitazone. Although no head-to-head trials have compared sitagliptin with vildagliptin, available data suggest that the two drugs have similar efficacy and safety profile (Mikhail 2008). Sitagliptin is given as 100-mg tablet po qd regardless of meal intake. Vildagliptin can be given as $50 \mathrm{mg}$ bid or $100 \mathrm{mg}$ qd, with no significant difference in efficacy between the two dosing regimens (Pi-Sunyer et al 2007). The smaller dose of vildagliptin $50 \mathrm{mg} \mathrm{qd}$ is infrequently used and appears less effective than the 100-mg dose (Pi-Sunyer et al 2007).

\section{Efficacy parameters}

Effects on hemoglobin A Ic (HbAlc) levels

In patients with type 2 diabetes receiving pioglitazone 30 to $45 \mathrm{mg}$ qd (mean baseline HbA1c 8\%), the addition of sitagliptin (100 mg qd) was associated with a mean reduction in $\mathrm{HbA} 1 \mathrm{c}$ values of $0.8 \%$ and $0.7 \%$ after 24 weeks compared with baseline and placebo, respectively (Rosenstock et al 2006). Similar results were obtained with the addition of vildagliptin to patients with type 2 diabetes inadequately controlled (average baseline HbA1c 8.7\%) on maximal pioglitazone doses (45 mg/day). Thus, the mean reductions in $\mathrm{HbAlc}$ values with vildagliptin $50 \mathrm{mg}$ bid were $1.0 \%$ and $0.7 \%$ compared with baseline and placebo, respectively (Garber et al 2007). In a third trial, drug-naïve patients with inadequate glycemic control (mean baseline $\mathrm{HbA} 1 \mathrm{c} \sim 8.7 \%$ ) were randomized to 4 groups to receive pioglitazone $30 \mathrm{mg}$ qd, vildagliptin $50 \mathrm{mg}$ qd plus pioglitazone $15 \mathrm{mg}$, vildagliptin $100 \mathrm{mg}$ plus pioglitazone $30 \mathrm{mg} \mathrm{qd}$, and vildagliptin $100 \mathrm{mg} \mathrm{qd}$ (Rosenstock et al 2007). After 24 weeks, mean reductions in $\mathrm{HbA} 1 \mathrm{c}$ from baseline were $1.4 \%$ with pioglitazone monotherapy, $1.7 \%$ with $50 / 15 \mathrm{mg}$ combination, $1.9 \%$ with $100 / 30 \mathrm{mg}$ combination, and $1.1 \%$ with vildagliptin monotherapy (Garber et al 2007). Thus, the effect of the previous drug combination on $\mathrm{HbA} 1 \mathrm{c}$ levels was less than additive, ie, the combination of pioglitazone $30 \mathrm{mg}$ qd plus vildagliptin $100 \mathrm{mg}$ qd resulted in $\mathrm{HbA} 1 \mathrm{c}$ reduction of $1.9 \%$, which was smaller in magnitude than the sum of the HbA1c reduction achieved by pioglitazone monotherapy (1.4\%) plus vildagliptin monotherapy (1.1\%). The combination of metformin plus sitagliptin appears to have similar efficacy, $1.9 \%$ with sitagliptin $50 \mathrm{mg}$ bid + metformin $1,000 \mathrm{mg}$ bid, $0.7 \%$ with sitagliptin $100 \mathrm{mg} \mathrm{qd}$, and $1.1 \%$ with metformin $1000 \mathrm{mg}$ bid (Goldstein et al 2007). Importantly, the time course of change in HbA1c values after initiation of therapy showed maximal reductions at 16 to 18 weeks followed by a plateau (Rosenstock et al 2006, 2007; Garber et 2007). The proportions of patients who achieved the target HbA1c levels $<7 \%$ at the end of trials increased with the combination of pioglitazone plus sitagliptin $100 \mathrm{mg}$ qd or vildagliptin $50 \mathrm{mg}$ bid to $36 \%$ to $65 \%$ versus $15 \%$ to $43 \%$ with pioglitazone monotherapy (Rosenstock et al 2006, 2007; Garber et 2007).

\section{Effects on fasting plasma glucose}

Two studies have shown significantly greater reduction in levels of fasting plasma glucose of $\sim 17 \mathrm{mg} / \mathrm{dL}$ with the addition of sitagliptin $100 \mathrm{mg}$ qd (Rosenstock et al 2006) or vildagliptin $50 \mathrm{mg}$ bid (Rosenstock et al 2007) to pioglitazone 30 to $45 \mathrm{mg}$ /day compared with pioglitazone monotherapy. However, in the third trial, the difference in fasting plasma glucose levels between patients receiving vildagliptin 
Table I Overview of trials of combination of DPP-4 inhibitors with pioglitazone

\begin{tabular}{|c|c|c|c|}
\hline Clinical trial & Rosenstock et al 2006 & Garber et al 2007 & Rosenstock et al 2007 \\
\hline Mean age (years) & 56 & 54 & 52 \\
\hline $\begin{array}{l}\text { Patient number } \\
\text { at randomization }\end{array}$ & 353 & 463 & 607 \\
\hline $\begin{array}{l}\text { Approximate gender } \\
\text { proportions (\%) } \\
\text { men/women }\end{array}$ & $55 / 45$ & $50 / 50$ & $60 / 40$ \\
\hline $\begin{array}{l}\text { Caucasian or white } \\
\text { race }\end{array}$ & $72 \%$ & $81 \%$ & $40 \%{ }^{\mathrm{a}}$ \\
\hline $\begin{array}{l}\text { Mean body mass } \\
\text { index }\left(\mathrm{kg} / \mathrm{m}^{2}\right)\end{array}$ & 31.5 & 32.5 & $29^{a}$ \\
\hline $\begin{array}{l}\text { Mean duration of } \\
\text { diagnosed diabetes } \\
\text { (years) }\end{array}$ & 6.1 & 4.6 & 2 \\
\hline $\begin{array}{l}\text { Drug treatment } \\
\text { before randomization }\end{array}$ & Pioglitazone $30-45$ qd & Pioglitazone $45 \mathrm{mg}$ qd & Drug-naïve \\
\hline Baseline mean $\mathrm{HbAlc}$ & $8 \%$ & $8.7 \%$ & $8.7 \%$ \\
\hline Design & $\begin{array}{l}\text { Randomized, double- } \\
\text { blind, placebo-controlled }\end{array}$ & Randomized, double-blind, placebo-controlled & Randomized, double-blind, double-dummy \\
\hline Patient groups & $\begin{array}{l}2 \text { groups: sitagliptin } \\
100 \mathrm{mg} \text { qd + pioglitazone } \\
30-45 \mathrm{mg} \text { qd }(\mathrm{n}=175) \\
\text { and sitagliptin } 100 \mathrm{mg} \\
\text { qd + placebo }(\mathrm{n}=178)\end{array}$ & $\begin{array}{l}3 \text { groups: vildagliptin } 50 \mathrm{mg} \text { qd + pioglitazone } \\
45 \mathrm{mg} \text { qd ( } \mathrm{n}=147) \text {, vildagliptin } 50 \mathrm{mg} \\
\text { bid + pioglitazone } 45 \mathrm{mg} \text { qd }(\mathrm{n}=158) \text {, and } \\
\text { placebo + pioglitazone } 45 \mathrm{mg} \text { qd }(\mathrm{n}=158)\end{array}$ & $\begin{array}{l}4 \text { groups: pioglitazone } 30 \mathrm{mg} \\
\text { qd }(n=161) \text {, vildagliptin } 100 \mathrm{mg} \text { qd + } \\
\text { pioglitazone } 30 \mathrm{mg} \text { qd }(\mathrm{n}=148) \text {, vilda- } \\
\text { gliptin } 50 \mathrm{mg} \text { qd + pioglitazone } 15 \mathrm{mg} \text { qd } \\
(\mathrm{n}=144) \text {, vildagliptin } 100 \mathrm{mg}(\mathrm{n}=153)\end{array}$ \\
\hline Follow-up & 24 weeks & 24 weeks & 24 weeks \\
\hline $\begin{array}{l}\text { Completion rates in } \\
\text { various groups }\end{array}$ & $85 \%-89 \%$ & $78 \%-84 \%$ & $80 \%-88 \%$ \\
\hline $\begin{array}{l}\text { Mean HbAlc reduc- } \\
\text { tion in sitagliptin } \\
\text { or vildagliptin groups }\end{array}$ & $\begin{array}{l}0.7 \% \text { with sitagliptin vs } \\
\text { placebo }\end{array}$ & $\begin{array}{l}0.5 \% \text { with vildagliptin } 50 \mathrm{mg} \text { vs placebo, and } \\
0.7 \% \text { with vildagliptin } 50 \mathrm{mg} \text { bid vs placebo }\end{array}$ & $\begin{array}{l}\text { I. } 4 \% \text { with pioglitazone } 30 \mathrm{mg} \text { qd, I.9\% } \\
\text { with vildagliptin } 100 \mathrm{mg} \text { qd+ pioglitazone } \\
30 \mathrm{mg} \text { qd, I.7\% with vildagliptin } 50 \mathrm{mg} \\
\text { qd + pioglitazone } 15 \mathrm{mg} \text { qd, and I. } 1 \% \\
\text { with vildagliptin } 100 \mathrm{mg} \text { vs baseline }\end{array}$ \\
\hline $\begin{array}{l}\text { Proportions of patients } \\
\text { with } \mathrm{HbAlc}<7 \% \text { at } \\
\text { the end of trials }\end{array}$ & $\begin{array}{l}23 \% \text { with placebo vs } 45 \% \\
\text { with sitagliptin }\end{array}$ & $\begin{array}{l}15 \% \text { with placebo, } 29 \% \text { with vildagliptin } \\
50 \mathrm{mg} \text { qd, } 36 \% \text { with vildagliptin } 50 \text { bid }\end{array}$ & $\begin{array}{l}43 \% \text { with pioglitazone } 30 \mathrm{mg} \text { qd, } 43 \% \\
\text { with vildagliptin } 100 \mathrm{mg} \text { qd, } 52 \% \text { with } \\
50 / 15 \text { combination, } 65 \% \text { with } 100 / 50 \\
\text { combination }\end{array}$ \\
\hline
\end{tabular}

aln this trial, $45 \%$ of patients were Asian, which may explain the relatively low body mass index.

$50 \mathrm{mg}$ bid plus pioglitazone $45 \mathrm{mg}$ qd and those receiving placebo plus pioglitazone was $\sim 10 \mathrm{mg} / \mathrm{dL}$, and did not reach statistical significance (Garber et al 2007).

\section{Effects on postprandial plasma glucose}

Based on their incretin effects, DPP-4 inhibitors act mainly by lowering blood glucose levels after meals. In the two trials that evaluated this glycemic parameter, the decrease in postprandial plasma glucose (PPG) values after a standard meal test was significantly greater with the vildaglitin-pioglitazone combination compared with pioglitazone-placebo combination (Garber et al 2007; Rosenstock et al 2007). However, the difference in PPG levels between the two groups was somewhat lesser than that expected, averaging 34 to $36 \mathrm{mg} / \mathrm{dL}$ with the high dose of vildagliptin (100 mg/day) (Garber et al 2007; Rosenstock et al 2007). Indeed, the corresponding reduction in PPG was greater $(\sim 47 \mathrm{mg} / \mathrm{dL})$ in trials using DPP-4 inhibitors as monotherapy despite similar baseline PPG values ( $\sim 250-260 \mathrm{mg} / \mathrm{dL}$ ) (Aschner et al 2006; Raz et al 2006). The explanation of this discrepancy is unclear, but could be related to differences in patients' characteristics and protocol of the meal tolerance test used. In addition, only a subset of patients, that might not be representative of the whole study group, was selected to undergo the meal tolerance test. 


\section{Safety of the combination of DPP-4 inhibitors and pioglitazone Effect on hypoglycemia}

Consistent with the glucose-dependent insulinotropic effect of incretin-based therapy (Mikhail 2006), the addition of sitagliptin or vildagliptin to pioglitazone did not result in a significant increase in the incidence or severity of hypoglycemia. Overall, the incidence of hypoglycemia was uncommon $(<2 \%$ ), and none of the episodes was severe (Rosenstock et al 2006, 2007; Garber et al 2007).

\section{Effect on weight}

Weight gain is the most common adverse effect of drugs pertaining to the TZD class. In a large-scale randomized trial, the use of pioglitazone was associated with an average weight gain of $4 \mathrm{~kg}$ compared with placebo after a mean follow-up of 34.5 months (Dormandy et al 2005). On the other hand, DPP-4 inhibitors have generally neutral effect on weight (Mikhail 2008). Thus, the addition of sitagliptin $100 \mathrm{mg}$ qd to pioglitazone $30-45 \mathrm{mg}$ qd did not result in significant weight gain compared with the addition of placebo to pioglitazone, the average weight gain after 24 weeks being 1.8 and $1.5 \mathrm{~kg}$ in the combination group and pioglitazone monotherapy group, respectively (Rosenstock et al 2006). Yet, the combination of vildagliptin $100 \mathrm{mg}$ /day plus pioglitazone $45 \mathrm{mg}$ qd was associated with greater weight gain $(2.7 \mathrm{~kg})$ compared with pioglitazone monotherapy $(1.4 \mathrm{~kg})$, $(p=0.03)$ (Garber et al 2007). Likewise, the high-dose combination pioglitazone $30 \mathrm{mg}$ qd/vildagliptin $100 \mathrm{mg}$ qd was associated with a trend toward more weight gain $(2.1 \mathrm{~kg})$ compared with pioglitazone monotherapy $30 \mathrm{mg}$ qd $(1.4 \mathrm{~kg})$ (Rosenstock et al 2007). Taken together, the addition of DPP-4 inhibitors to pioglitazone may have either negligible effect or may slightly exacerbate the weight gain induced by pioglitazone.

\section{Effects on edema}

Peripheral edema is another common adverse effect of TZDs. In one trial, peripheral edema occurred more frequently in patients randomized to vildagliptin plus pioglitazone $45 \mathrm{mg}$ qd than to placebo plus pioglitazone $45 \mathrm{mg}$ qd (Garber et al 2007). Thus, edema was reported by $8.2 \%$, $7 \%$, and $2.5 \%$ of patients receiving vildagliptin $50 \mathrm{mg} \mathrm{qd}$, vildagliptin $50 \mathrm{mg}$ bid, and placebo, respectively. However, the excess incidence in edema was not observed in 2 other trials using vildagliptin or sitagliptin in addition to pioglitazone (Rosenstock et al 2006, 2007). The reasons for this discrepancy are unclear, but may be related in part to the pioglitazone doses. Indeed, the low-dose combination of pioglitazone $15 \mathrm{mg}$ plus vildagliptin $50 \mathrm{mg}$ qd was associated with low incidence of edema (3.5\%) and also of weight gain (1.4 kg) compared with the high-dose combination formed of pioglitazone $30 \mathrm{mg}$ plus vildagliptin $50 \mathrm{mg}$ bid which was associated with higher incidence of edema (9.3\%) and weight gain $(2.1 \mathrm{~kg})$ (Rosenstock et al 2007). Interestingly, the use of low-dose combination formed of pioglitazone $15 \mathrm{mg} /$ vildagliptin $50 \mathrm{mg}$ led to a mean in HbAlc levels of $1.7 \%$, a reduction not significantly different from the reduction associated with the high-dose combination (1.9\%) (Rosenstock et al 2007). Therefore, the low-dose combination may be a more appropriate option if edema or weight gain becomes a concern.

\section{Effects on plasma lipids}

Pioglitazone in maximum doses (45 mg qd) has been shown to raise plasma levels of high-density lipoprotein-cholesterol (HDL-C) and low-density lipoprotein cholesterol (LDL-C) by up to $15 \%$, and lowers triglycerides by $\sim 12 \%$ compared with baseline values after 24 weeks (Goldberg et al 2005). Conversely, studies of DPP-4 inhibitors overall did not show significant effects on plasma lipoproteins (Mikhail and Cope 2007). When sitagliptin or vildagliptin was added to ongoing pioglitazone therapy, no significant changes in plasma lipids occurred (Garber et al 2007; Rosenstock et al 2007). Meanwhile, when used as initial therapy in treatment-naïve patients, the high-dose combination formed of vildagliptin $50 \mathrm{mg}$ bid and pioglitazone $30 \mathrm{mg}$ was associated with significantly lower LDL-C (by 10\%) and non-HDL-C (by 7\%) compared with pioglitazone monotherapy (Rosenstock et al 2007). Levels of triglycerides and HDL-C were not significantly different between the two groups (Rosenstock et al 2007). Taken together, the addition of DPP-4 inhibitors to pioglitazone either has no effect or may improve some lipid parameters such as LDL-C levels.

\section{Effect on insulin sensitivity}

No significant effect was found on insulin sensitivity when sitagliptin or vildagliptin was added to ongoing pioglitazone therapy (Garber et al 2007; Rosenstock et al 2006). In fact, most (Pratley et al 2006; Raz et al 2006; Hanefeld et al 2007; Garber et al 2008), but not all (Azuma et al 2008; Utzschneider et al 2008) studies have shown that DPP-4 inhibitors did not enhance insulin sensitivity. Methods of measurements of insulin resistance may be one factor explaining discrepant results. Nevertheless, on balance, the 
strength of data suggests that DPP-4 inhibitors have no major impact on insulin resistance.

\section{Other adverse effects}

In general, the addition of sitagliptin or vildagliptin to pioglitazone was well tolerated without serious adverse effects. However, discontinuation rates due to adverse effects were slightly higher with combination therapy compared with the pioglitazone monotherapy. The highest difference in discontinuation rates was reported between the combination of sitagliptin $100 \mathrm{mg}$ qd plus pioglitazone 30 to $45 \mathrm{mg}$ qd versus placebo plus pioglitazone 30 to $45 \mathrm{mg} \mathrm{qd}, 6 \%$ and $1 \%$, respectively $(\mathrm{p}<0.05$ ). Unfortunately, the authors did not specify the type of adverse effects that led to drug discontinuation (Rosenstock et al 2006).

\section{Clinical implications}

The combination of DPP-4 inhibitors and pioglitazone provides several advantages. First, because of their distinct mechanism of action, DPP-4 inhibitors combined with pioglitazone lower $\mathrm{HbA1c}$ with approximately the same magnitude observed in trials of DPP-4 inhibitors used as monotherapy, ie, $\sim 0.7 \%$ mean reduction versus baseline after 24 weeks in patients with average $\mathrm{HbA} 1 \mathrm{c}$ of $\sim 8.5 \%$ at study entry (Aschner et al 2006; Raz et al 2006). Second, the DPP-4 inhibitors/pioglitazone combination is generally well tolerated. Third, the addition of DPP-4 inhibitors to pioglitazone does not increase the frequency or the severity of hypoglycemia (Rosenstock et al 2006, 2007; Garber et al 2007). Fourth, the administration of the combination is simple, and both drugs can be taken orally once daily irrespective of meal intake. Furthermore, sitagliptin and pioglitazone can be used in renal insufficiency (see below).

Meanwhile, current DPP-4 inhibitors have important limitations. First, in terms of efficacy, the addition of a DPP-4 inhibitor to pioglitazone raised the proportions of patients who achieved the goal of HbA1c value below 7\% from $15 \%$ to $43 \%$ with pioglitazone monotherapy to $36 \%$ to $65 \%$, ie, the drug combination allowed $\sim 20 \%$ more patients to attain optimum glycemic control, a fact that underscores its moderate efficacy and the difficulty of optimizing diabetes control in general. Second, data regarding the efficacy and safety of the DPP-4 inhibitor/pioglitazone combination beyond 24 weeks are lacking. Vildagliptin in combination with metformin was evaluated in studies lasting one year (Ahren et al 2004) and as monotherapy for up to 2 years (Goke et al 2008), whereas sitagliptin was evaluated as monotherapy for up to 1 year (Nauck et al 2007). Third, the cost of the combination of
pioglitazone/DPP-4 inhibitor is higher than the commonly used combination formed of metformin and a sulfonylurea, but the exact difference in cost is unclear at present. Fourth, although all the trials that evaluated the combination were double-blinded and generally of good quality, they were sponsored by the corresponding manufacturer, and therefore may be open to different bias. Moreover, those trials excluded patients with different co-morbidities; therefore the results may not be applicable to sicker patients encountered in clinical practice.

In view of the above limitations, metformin will remain the oral drug of choice for initial treatment of type 2 diabetes due to multiple advantages such as reassuring long-term safety, acceptable efficacy, induction of mild weight loss, low propensity for causing hypoglycemia, and low-cost (Nathan et al 2006; Bolen et al 2007). If glycemic control is not achieved with metformin alone, one or more of the following agents can be added: a sulfonylurea, a TZD, a DPP-4 inhibitor, exenatide, or insulin depending on the extent of metabolic deterioration, patient's preference, and local resources. For example, in an obese patient concerned about further weight gain or hypoglycemia, the combination of metformin plus a DPP-4 inhibitor seems appropriate.

Meanwhile, the combination of DPP-4 inhibitors and pioglitazone can be particularly useful in the following situations:

1. Patients who do not tolerate metformin or a sulfonylurea due to adverse effects (eg, diarrhea with metformin and hypoglycemia with a sulfonylurea).

2. Patients with renal insufficiency in whom metformin is contraindicated. Currently, sitagliptin is the only DPP-4 inhibitor that may be used in various degrees of renal impairment including patients on hemodialysis (see Table 2 for dosage adjustment in renal insufficiency) (Januvia ${ }^{\circledR}$ package insert 2007; Chan et al 2008). Meanwhile, safety data regarding the use of vildagliptin in renal insufficiency are not yet available. With respect to pioglitazone, pharmacokinetic studies suggest that the drug may be safely used in maximum doses (45 mg qd) in renal failure (Budde et al 2003). However, caution should be exercised in the latter situation, as renal failure appears to increase the risk of heart failure and pulmonary edema in TZD-treated patients (Kermani and Garg 2003; Manley and Allock 2003).

The advantages and limitations of the combination of DPP-4 inhibitors with pioglitazone are summarized in Table 2. 
Table 2 Advantages and limitations of the DPP-4 inhibitor/ pioglitazone combination

\author{
Advantages \\ DPP-4 inhibitors generally maintain consistent efficacy for HbAlc \\ reduction similar to trials of monotherapy of DPP-4 inhibitors. \\ Easy administration with possible once daily dosing irrespective of meal \\ intake. \\ Generally well tolerated. \\ No increase in risk of hypoglycemia. \\ Absence of or minimal extra weight gain $(\sim \mathrm{lg})$ compared \\ with pioglitazone monotherapy \\ Can be particularly useful in patients who cannot take metformin \\ or sulfonylurea \\ Can be used with renal insufficiency ${ }^{\mathrm{a}}$

\section{Limitations} \\ Moderate efficacy \\ Associated with weight gain $(\sim 1.5 \mathrm{~kg}$ on the average) and \\ edema (3\%-9\%) attributed to the pioglitazone component. \\ Lack of long-term efficacy and safety data on the DPP-4 inhibitors \\ Relatively high cost \\ Bias in presenting data cannot be ruled out.
}

aln cases of moderate renal dysfunction (creatinine clearance between 30-49 ml/min or approximate serum creatinine levels between 1.8 and $3 \mathrm{mg} / \mathrm{dL}$ in men, and 1.6 and $2.5 \mathrm{mg} / \mathrm{dL}$ in women), it is recommended to decrease the dose of sitagliptin to 50 $\mathrm{mg}$ once daily. In more advanced renal dysfunction and patients on hemodialysis, the recommended dose is $25 \mathrm{mg}$ once daily (Januvia ${ }^{\circledR}$ package insert 2007).

\section{Future directions}

Long-term randomized trials are needed to examine the safety of the combination of pioglitazone and DPP-4 inhibitors, its effects on hard endpoints such as cardiovascular morbidity and mortality, and its impact on the course of diabetes and $\beta$-cell function. Moreover, direct comparison with other drug combinations is required to help determine the safest and most effective approach of combination therapy in type 2 diabetes.

\section{Acknowledgment}

The author thanks Marsha Kmec who provided expert assistance in the literature review.

\section{Disclosures}

The author has no conflicts of interest to disclose.

\section{References}

Ahren B, Gomis R, Standl E, et al. 2004. Twelve- and 52-week efficacy of the dipeptidyl peptidase IV inhibitor LAF237 in metformin-treated patients with type 2 diabetes. Diabetes Care, 27:2874-80.

Ahren B. 2008. Novel combination treatment of type 2 diabetes: DPP-4 inhibition + metformin. Vasc Health Risk Manag, 4:382-94.

Aschner P, Kipnes MS, Lunceford JK, et al. 2006. Effect of the dipeptidyl peptidase-4 inhibitor sitagliptin as monotherapy on glycemic control in patients with type 2 diabetes. Diabetes Care, 29:2632-7.
Azuma K, Radikova Z, Mancino J, et al. 2008. Measurements of islet function and glucose metabolism with the dipeptidyl peptidase 4 inhibitor vildagliptin in patients with type 2 diabetes. J Clin Endocrinol Metab, 93:459-64.

Bolen S, Feldman L, Vassy J, et al. 2007. Systemic review: Comparative effectiveness and safety of oral medications for type 2 diabetes mellitus. Ann Intern Med, 147:386-99.

Budde K, Neumayer H, Fritsche L, et al. 2003. The pharmacokinetics of pioglitazone in patients with impaired renal function. $\mathrm{Br} J \mathrm{Clin}$ Pharmacol, 55:368-74.

Chan JC, Scott R, Ferreira A, et al. 2008. Safety and efficacy of sitagliptin in patients with type 2 diabetes and chronic renal insufficiency. Diabetes Obes Metab, 10:545-55.

Dormandy JA, Charbonnel B, Eckland DJA. 2005. Secondary prevention of macrovascular events in patients with type 2 diabetes in the PROactive Study (PROspective pioglitAzone Clinical Trial In macrovascular Events): a randomized controlled trial. Lancet, 366:1279-89.

Drucker DJ, Nauck MA. 2006. The incretin system: glucagon-like peptide1 receptor agonists and dipeptidyl peptidase- 4 inhibitors in type 2 diabetes. Lancet, 368:1696-705.

Garber AJ, Schweizer A, Baron A, et al. 2007. Vildagliptin in combination with pioglitazone improves glycaemic control in patients with type 2 diabetes failing thiazolidinedione monotherapy: a randomized, placebocontrolled study. Diabetes Obes Metab, 9:166-74.

Garber AJ, Foley JE, Banerji A, et al. 2008. Effects of vildagliptin on glucose control in patients with type 2 diabetes inadequately controlled with a sulfonylurea. Diabetes Obes Metab. [Epub ahead of print].

Goke B, Hershon K, Kerr D, et al. 2008. Efficacy and safety of vildagliptin monotherapy during 2-year treatment of drug-naive patients with type 2 diabetes: comparison with metformin. Horm Metab Res. [Epub ahead of print].

Goldstein BJ, Feinglos MN, Lunceford JK, et al. 2007. Effect of initial combination therapy with sitagliptin, a dipeptidyl peptidase-4 inhibitor, and metformin on glycemic control in patients with type 2 diabetes. Diabetes Care, 30:1979-87. Erratum: Diabetes Care, 2008; 31:1713.

Hanefeld M, Herman GA, Wu M, et al. 2007. Once-daily sitagliptin, a dipeptidyl peptidase- 4 inhibitor, for the treatment of patients with type 2 diabetes. Curr Med Res Opin, 23:1329-1339.

Januvia $^{\circledR}$ (sitagliptin phosphate) package insert. 2007. Merk and Co., Inc., Whitehouse Station, NJ 08889, USA.

Kermani A, Garg A. 2003. Thiazolidinedione-associated congestive heart failure and pulmonary edema. Mayo Clin Proc, 78:1088-91.

Manley HJ, Allock NM. 2003. Thiazolidinedione safety and efficacy in ambulatory patients receiving hemodialysis. Pharmacotherpay, $23: 861-5$.

Mikhail N. 2006. Exenatide: a novel approach for treatment of type 2 diabetes. South Med J, 99:1271-9.

Mikhail N, Cope D. 2007. The role of DPP-4 inhibitors in type 2 diabetes. Patient Care, August:18-24.

Mikhail N. 2008. Incretin mimetics and dipeptidyl peptidase inhibitors in clinical trials for the treatment of type 2 diabetes. Expert Opin Investig Drugs, 17:845-53.

Nathan DM, Buse JB, Davidson M, et al. 2006. Management of hyperglycemia in type 2 diabetes: A consensus algorithm for the initiation and adjustment of therapy. Diabetes Care, 29:1963-72.

Nauck MA, Meininger G, Sheng D, et al; for the Sitagliptin Study 024 Group. 2007. Efficacy and safety of the dipeptidyl peptidase-4 inhibitor, sitagliptin compared with the sulfonylurea, glipizide, in patients with type 2 diabetes inadequately controlled on metformin alone: a randomized, double-blind, non-inferiority trial. Diabetes Obes Metab, 9:194-205.

Pi-Sunyer FX, Schweizer A, Mills D, et al. 2007. Efficacy and tolerability of vildagliptin monotherapy in drug-naive patients with type 2 diabetes. Diabetes Res Clin Pract, 76: 132-8.

Pratley RE, Jauffret-Kamel S, Galbreath E, et al. 2006. Twelve-week monotherapy with the DPP-4 inhibitor vildagliptin improves glycemic control in subjects with type 2 diabetes. Horm Metab Res, 38:423-8. 
Raz I, Hanefeld M, Xu L, et al; for the Sitagliptin Study 023 Group. 2006. Efficacy and safety of the dipeptidyl peptidase-4 inhibitor sitagliptin as monotherapy in patients with type 2 diabetes mellitus. Diabetologia, 49:2564-71.

Rosenstock J, Brazg R, Andryuk PJ, et al; for the Sitagliptin Study 019 Group. 2006. Efficacy and safety of the dipeptidyl peptidase-4 inhibitor sitagliptin added to ongoing pioglitazone therapy in patients with type 2 diabetes: a 24-week, multicenter, randomized, double-blind, placebo-controlled, parallel-group study. Clin Ther, 28:1556-68.

Rosenstock J, Baron MA, Camisasca RP, et al. 2007. Efficacy and tolerability of initial combination therapy with vildagliptin and pioglitazone compared with component monotherapy in patients with type 2 diabetes. Diabetes Obes Metab, 9:175-85.
Utzschneider KM, Tong J, Montgomery B, et al. 2008. The dipeptidyl peptidase-4 inhibitor vildagliptin improves beta-cell function and insulin sensitivity in subjects with impaired fasting glucose. Diabetes Care, 31:108-13.

Vella A, Bock G, Giesler PD, et al. 2007. Effects of dipeptidyl peptidase inhibition on gastrointestinal function, meal appearanace, and glucose metabolism in type 2 diabetes. Diabetes, 56:1475-80.

Vilsboll T, Agerso H, Krarup T, et al. 2003. Similar elimination rates of glucagon-like peptide-1 in obese type 2 diabetic patients and healthy subjects. J Clin Endocrinol Metab, 88:220-4.

Yki-Jarvinen H. 2004. Drug therapy: Thiazolidinediones. N Engl J Med, 351:1106-18. 
